\title{
Economic viability of pineapple residues recycling
}

\begin{abstract}
A study was conducted to investigate whether pineapple residues removal before replanting (RM2) could serve as an economically competitive alternative to the existing in situ burning of pineapple residues before replanting (RM1). The Net Present Value (NPV) was used to compare the economic viability of the two residue management practices. Taking into account the cost of environmental pollution associated with burning of pineapple residues, the NPV analysis revealed that RM2 can serve as an economically competitive alternative to RM1. Article copies available for a fee from The Haworth Document Delivery Service: 1800-HAWORTH. E-mail address: docdeliveryhaworthpress.com Website: http://www.HaworthPress.com (C) 2003 by The Haworth Press, Inc. All rights reserved.
\end{abstract}

Keyword: Economic viability; Fruit yield; Peat; Pineapple residues recycling 